\title{
ANALISIS PENGARUH GAYA KEPEMIMPINAN, KEPUASAN KERJA TERHADAP KINERJA TENAGA KEPENDIDIKAN
}

\author{
Diah Aryanti Sapto Warsi ${ }^{1}$ \\ Lilik Siswanta ${ }^{2}$ \\ Endang Tri Wahyuni ${ }^{3}$ \\ Sukhemi ${ }^{4}$ \\ ${ }^{1}$ Universitas PGRI Yogyakarta, email : diah@upy.ac.id \\ ${ }^{2}$ Universitas PGRI Yogyakarta, email : liliksiswanta@gmail.com \\ ${ }^{3}$ Universitas PGRI Yogyakarta, email : endang@upy.ac.id \\ ${ }^{4}$ Universitas PGRI Yogyakarta, email : khemi_mukh@yahoo.co.id
}

\begin{abstract}
The purpose of this study is to analyse and prove the influence of leadership style, job satisfaction on the employees performance at the University of PGRI Yogyakarta. The total sample of 56 respondents drawn using proportional random sampling, and data analysis techniques using Structural Equations Modeling (SEM) with the help of PLS software. The results of the study explained that occurred a significant effecy on the latent exogenous variables that influence leadership style, job satisfaction in improving the performance of (endogenous latent variables). This is demonstrated by the significant figures and valid in every model tested.
\end{abstract}

Keyword : Leadership style, job satisfaction, performance

\section{PENDAHULUAN}

Universitas PGRI Yogyakarta merupakan salah satu Perguruan Tinggi Swasta yang mempunyai harapan besar dan bertumbuh secara exponential dalam menghadapi persaingan dunia pendidikan. Sebagai salah satu aset sumber daya manusia, softskill tenaga kependidikan harus diperhatikan untuk meningkatkan kualitas yang dimiliki. Pada kondisi ini faktor kepemimpinan sangat dibutuhkan karena kepemimpinan adalah langkah atau tindakan seorang pemimpin dalam memotivasi bawahannya agar mampu menyelesaikan tugas sehingga tujuan organisasi dapat tercapai. Selain pemimpin yang memiliki kualitas, organisasi juga membutuhkan pemimpin yang mampu mengkondisikan keadaan, yang artinya mampu memberikan kepuasan kerja bagi karyawan dan dapat meningkatkan kinerja karyawannya.

Faktor kepuasan kerja karyawan (tenaga kependidikan) dalam suatu organisasi sangat penting. Tenaga kependidikan yang mempunyai tingkat kepuasan kerja yang baik akan bekerja dengan rajin dan berperilaku positif terhadap pekerjaannya, sehingga kinerjanya akan meningkat dan kelangsungan hidup organisasi dapat dipertahankan. Kinerja yang baik akan meningkatkan rasa percaya diri bagi karyawan dalam menyelesaian tugas yang diberikan oleh pimpinan.

Bisman (Bisnis dan Manajemen): The Journal Of Business and Management 


\section{KAJIAN PUSTAKA}

\section{Gaya Kepemimpinan}

Wukir (2013), menyatakan kepemimpinan merupakan seni memotivasi dan mempengaruhi sekelompok orang untuk bertindak mencapai tujuan bersama. Seseorang pemimpin memiliki kewenangan untuk mengarahkan bawahan mengerjakan sebagian dari pekerjaannya, menggunakan wewenang formal dalam mengarahkan, mengorganisasikan dan mengontrol bawahan agar bertanggungjawab terhadap pekerjaan yang diberikan.

Pemimpin memiliki gaya kepemimpinan yang berbeda-beda satu dengan yang lain (Hidayat, Sudirja, et. All, 2018). Gaya kepemimpinan selain tergantung dari karakter atau sifat para pelaku pemimpin juga dipengaruhi oleh karakteristik bawahan dan lingkungan kerjanya. Jenis gaya kepemimpinan ada beberapa macam, namun dalam penelitian ini hanya mengambil 3 gaya kepemimpinan yaitu: 1) Gaya Kepemimpinan Otoriter; 2) Gaya Kepemimpinan Partisipasif, dan ; 3) Gaya Kepemimpinan Delegatif.

\section{Gaya Kepemimpinan Otoriter}

Gaya kepemimpinan otoriter adalah gaya kepemimpinan dimana kekuasaan atau wewenang sebagian besar mutlak pada pimpinan. Pemimpin yang memiliki gaya kepemimpinan otoriter atau sentralisasi wewengan dalam setiap pengambilan keputusan atau kebijakan tidak melibatkan bawahan. Fokus kepemimpinan hanya pada peningkatan produktivitas kerja tanpa memperhatikan perasaan dan kesejahteraan bawahan.

\section{Gaya Kepemimpinan Partisipasif}

Gaya kepemimpinan partisipasif adalah gaya kepemimpinan dengan cara persuasif, menciptakan kerjasama serasi, menumbuhkan loyalitas, dan partisipasi bawahan. Pemimpin yang memiliki gaya kepemimpinan partisipasif sering melibatkan bawahan terlibat dalam proses pengambilan keputusan dengan memberikan saran dan ide. Bawahan disorong dan dibina menerima tanggungjawab yang lebih besar.

\section{Gaya Kepemimpinan Delegatif}

Gaya kepemimpinan delegatif adalah gaya kepemimpinan yang mendelegasikan wewenangnya pada bawahan. Bawahan diberikan leluasa dalam menyelesaikan dan melaksanakan pekerjaannya. Pemimpinan tidak membuat peraturan-peraturan baku tentang pelaksanaan pekerjaan bawahan. Bawahan dituntut mandiri dalam mengerjakan tugas.

\section{Kepuasan Kerja}

Wibowo (2013:132), kepuasan kerja (job satisfaction) merupakan tingkat perasaaan senang seseorang sebagai penilaian positif terhadap pekerjaan dan lingkungan tempat kerjanya. Kepuasan kerja memiliki banyak dimensi, secara umum meliputi kepuasan terhadap pekerjaan itu sendiri, kepuasan terhadap gaji, kepuasan terhadap adanya pengakuan, kepuasan terhadap hubungan antara supervisor dan rekan kerja, serta kepuasan diberikan kesempatan untuk maju. 
Karyawan (tenaga kependidikan) yang memiliki kepuasan kerja yang tinggi akan memperhatikan kualitas kerjanya, mempunyai komitmen yang besar terdap organisasi dan lebih produktif sehingga kinerjanya akan meningkat.

\section{Kinerja}

Mangkunegara (2013:67), kinerja merupakan hasil kerja yang dapat dicapai oleh seseorang atau sekelompok orang dalam suatu organisasi sesuai dengan wewenang dan tanggungjawab masing-masing dalam rangka upaya mencapai tujuan organisasi secara legal, tidak melanggar hukum dan sesuai dengan moral dan etika. Ukuran kinerja dapat dilihat dari sisi jumlah dan mutu tertentu sesuai dengan standart yang telah ditetapkan oleh organisasi atau perusahaan.

Seorang pemimpin memiliki pengaruh yang besar dalam mendorong peningkatan kinerja para karyawan demi kemajuan organisasi, karena pemimpin bekerja keras tidak hanya untuk mensukseskan dirinya tetapi juga seluruh orang yang berada di organisasi tersebut. Berhasil tidaknya seorang pemimpin dalam menjalankan kepemimpinannya akan mempengaruhi kinerja karyawan (Yuniarti, 2014).

Puranto dan Wahyuddin (2015) menyatakan bahwa faktor kepuasan kerja mempunyai pengaruh paling dominan terhadap kinerja dibanding variabel lain. Rani Mariam (2009) menyatakan bahwa pimpinan harus memperhatikan benar prestasi kerja bawahan agar bawahan memiliki kepuasan kerja yang tinggi dengan sikap yang ditunjukkan oleh pimpinan.

\section{METODE PENELITIAN}

\section{Tahap Persiapan}

Tujuan tahap persiapan adalah untuk mempersiapkan perangkat penelitian setelah menganalisis dan mengelompokkan data pada masing-masing kategori. Data yang digunakan adalah data primer dan menggunakan data sekunder.

\section{Tahap Pelaksanaan}

Tahap pelaksanaan adalah melakukan uji coba instrumen. Metode pemilihan sampel yang digunakan Propotionate Stratified Random Sampling, dimana populasi mempunyai anggota atau unsur yang tidak homogen dan berstrata.

\section{Tahap Analisis Data}

Analisis Deskriptif

Analisis deskriptif dilakukan dengan membuat interval (range) bersasarkan pada masing-masing kategori, dengan rumus sebagai berikut :

Dimana:

$$
\text { Int }=\frac{\sum S_{\max }-\sum s_{\min }}{\sum_{i=1}^{n} K_{i}}
$$

$$
\begin{array}{ll}
\text { Int } & =\text { Interval } \\
\sum s_{\text {Max }} & =\text { Skor Total Maksimum } \\
\sum s_{\text {Min }} & =\text { Skor Toral Minimum }
\end{array}
$$

Bisman (Bisnis dan Manajemen): The Journal Of Business and Management 


$$
\sum_{i=1}^{n} K_{i} \quad=\text { Jumlah Kategori }
$$

\section{Analisis Inferensial}

Analisis inferensial menggunakan alat PLS (Partial Least Square), yaitu SEM yang berbasis variance, dengan software Smart PLS 3.0 (Wiyono, 2011), dengan kriteria penilaian PLS pada tabel 1 sebagai berikut:

\section{Tabel 1}

\section{Kriteria Penilaian PLS}

\begin{tabular}{|c|c|c|}
\hline $\begin{array}{c}\text { UJI } \\
\text { MODEL }\end{array}$ & OUTPUT & KRITERIA \\
\hline $\begin{array}{l}\text { Outer } \\
\text { Model } \\
\text { (Uji }\end{array}$ & $\begin{array}{l}\text { a. Convergent } \\
\text { Validity. }\end{array}$ & a.Nilai loading factor $>0,50$ \\
\hline Indikator) & $\begin{array}{l}b . \quad \text { Discriminan } \\
t \text { Validity. }\end{array}$ & $\begin{array}{l}\text { b. Nilai korelasi cross loading dengan } \\
\text { variabel latennya harus lebih besar } \\
\text { dibanding-kan korelasi terhadap variabel } \\
\text { laten yang lain. }\end{array}$ \\
\hline & $\begin{array}{l}\text { c. Composite } \\
\text { Reliability. }\end{array}$ & $\begin{array}{l}\text { c.Nilai Composite reliability yang baik } \\
\text { apabila memiliki nilai } \geq 0,70\end{array}$ \\
\hline $\begin{array}{l}\text { Inner } \\
\text { Model } \\
\text { (Uji }\end{array}$ & $\begin{array}{l}\text { a. } \mathrm{R}^{2} \text { untuk variabel } \\
\text { laten endogen }\end{array}$ & $\begin{array}{l}\text { a.Hasil R² sebesar } 0,67 ; 0,33 ; \text { dan } 0,19 \\
\text { mengindikasikan bahwa model "Baik", } \\
\text { "Moderat", dan"Lemah". }\end{array}$ \\
\hline Hipotesis) & $\begin{array}{l}\text { b. Koefisien } \\
\text { Parameter dan T- } \\
\text { Statistik }\end{array}$ & $\begin{array}{l}\text { b. Nilai estimasi untuk hubungan jalur } \\
\text { dalam model struktural harus signifikan, } \\
\text { yang dapat diperoleh dengan prosedur } \\
\text { bootstrapping. }\end{array}$ \\
\hline
\end{tabular}

Sumber : Wiyono, 2011

\section{Analisis Jalur}

Pengaruh langsung (direct effect), pengaruh tidak langsung (inderect effect) dan pengaruh total (total effect) menggunakan analisis jalur dengan formula sebagai berikut :

Pengaruh langsung (Direct Effect)

$$
\begin{array}{lll}
\mathrm{X} 1 \rightarrow \mathrm{X} 2 & = & \text { sesesar koefesien parameter sesuai output (a) } \\
\mathrm{X} 1 \rightarrow \mathrm{Y} & = & \text { sebesar koefesien parameter sesuai output (b) } \\
\mathrm{X} 2 \rightarrow & = & \text { sebesar koefesien parameter sesuai output (c) }
\end{array}
$$

Pengaruh Tidak Langsung (Indirect Efect)

$\mathrm{X} 1 \rightarrow \mathrm{X} 2 \rightarrow \mathrm{Y}=\quad$ sebesar a $\mathrm{X} \mathrm{c}(\mathrm{d})$

Pengaruh total (Total Effect)

$$
\mathrm{X} 1 \rightarrow \mathrm{X} 2 \rightarrow \mathrm{Y}=\quad \text { sebesar } \mathrm{a}+\mathrm{d}
$$




\section{KERANGKA PENELITIAN}

\section{Kerangka Pemikiran Teoritis}

Tujuan suatu organisasi dapat dicapai salah satunya dengan adanya peningkatan kinerja karyawan (tenaga kependidikan). Tingkat pencapaian hasil kinerja dapat dilihat secara kuantitas dan kualitas, efisien dan efektifitas, kerjasama, kreatif dan inovatif. Untuk meningkatkan kinerja tenaga kependidikan diperlukan adanya kepuasan kerja, karena merupakan bagian dari tuntutan hidup. Hal tersebut akan mempengaruhi perasaan tenaga kependidikan dan selanjutnya berdampak pada pelaksanaan aktivitas. Kepuasan kerja dan kinerja juga dipengaruhi gaya kepemimpinan yang dimiliki oleh pemimpin, karena karakter atau sifat para pelaku pemimpin akan mempengaruhi karakteristik bawahan dan lingkungan kerja suatu organisasi.

Uraian pemikiran di atas memberikan landasan arah pada penyusunan kerangka pemikiran teoritis sebagai berikut :

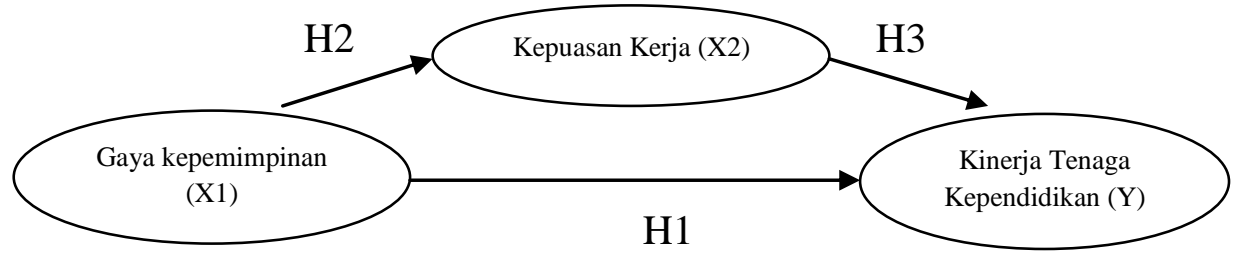

\section{Gambar 1. Kerangka Pemikiran Teoritis}

\section{DEFINISI OPERASIONAL}

\section{Gaya Kepemimpinan}

Gaya kepemimpinan merupakan pola perilaku dan strategi yang diterapkan oleh seorang pemimpin agar dapat mengorganisasikan, mengarahkan dan mengontrol bawahan sesuai dengan kewenangan yang dimiliki untuk mencapai tujuan organisasi. Indikator gaya kepemimpinan meliputi : otoriter (X1.1); Partisipasif (X1.2) dan Delegatif (X1.3).

\section{Kepuasan Kerja}

Kepuasan kerja menunjukkan kesesuaian harapan seseorang yang timbul dengan apa yang diharapkan oleh karyawan. Kepuasan kerja dapat dijadikan suatu ukuran proses pembangunan iklim yang berkelanjutan dalam suatu organisasi. Indikator kepuasan kerja : Kepuasan terhadap atasan (X2.1); Kepuasan terhadap rekan kerja (X2.2); Kepuasan terhadap pekerjaan (X2.3); Kepuasan terhadap peluang promosi (X2.4); dan Kepuasan terhadap pendapatan (X2.5).

\section{Kinerja Tenaga kependidikan}

Kinerja adalah hasil yang telah dicapai seseorang atau sekelompok orang dalam melaksanakan kerja atau tugas sesuai dengan wewenang dan tanggungjawab masing-masing dalam rangka mencapai tujuan organisasi. Pegawai yang berkualitas adalah pegawai yang kinerjanya dapat memenuhi target atau sasaran yang ditetapkan oleh organisasi. Indikator kinerja tenaga kependidikan : Kualitas hasil kerja meliputi keuletan kerja, kreativitas yang 
dimiliki dan kepedulian keselamatan kerja (Y1); Disiplin kerja meliputi tingkat tanggungjawab atas hasil pekerjaan (Y2); dan Kerjasama antar rekan kerja (Y3).

\section{Jenis dan Sumber Data}

Sugiyono (2015), data yang dipergunakan dalam penelitian ini adalah data yang bersifat kuantitatif karena dinyatakan dengan angka-angka yang menunjukkkan nilai terhadap besaran atas variabel yang diwakilinya dan sumber data yang dipergunakan adalah data primer dan data sekunder.

Data primer diperoleh secara langsung dari penyebaran daftar pertanyaan kuesioner dan data sekunder yang digunakan adalah data tenaga kependidikan Universitas PGRI Yogyakarta yang sudah berstatus sebagai pegawai tetap.

\section{Populasi dan Sampel}

Populasi dalam penelitian ini berjumlah 56 orang. Metode pemilihan sampel menggunakan proportionate stratified random. Kriteria subyek yang digunakan adalah : a) Tenaga kependidikan Universitas PGRI Yogyakarta, b) Pendidikan terakhir, dan c) Memiliki masa kerja 1 tahun ke atas, dikarenakan pada tahun pertama kerja dianggap sebagai masa percobaan).

\section{PEMBAHASAN DAN HASIL}

\section{Analisis Inferensial}

Analisis inferensial dilakukan berdasarkan hasil uji model struktural (inner model) yang meliputi output $\mathrm{R}^{2}$, koefisien parameter dan $P$ Value.

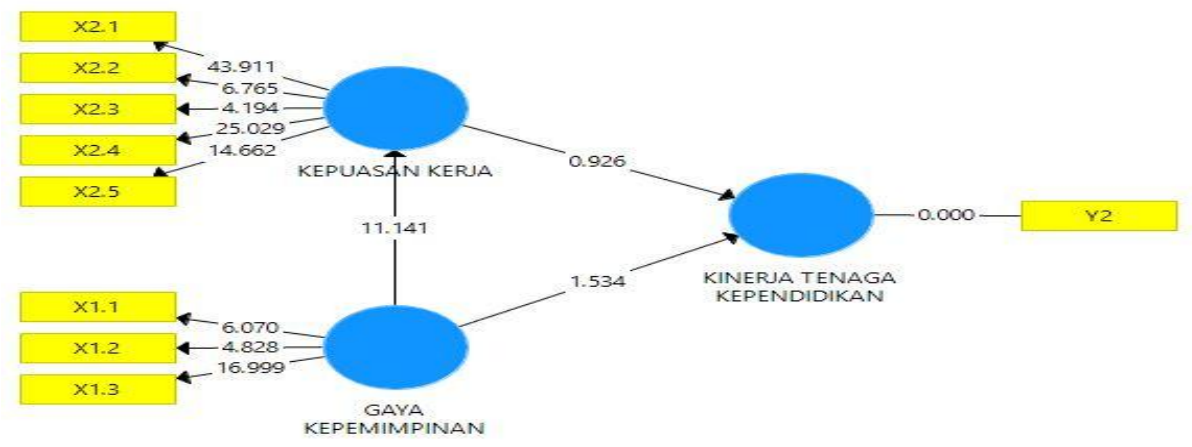

Gambar 2

Model Bootstraping Setelah Uji Indikator

Dari Gambar 2 dapat dijelaskan bahwa covariabel pengukuran indikator dipengaruhi oleh konstruk laten atau mencerminkan variasi dari konstruk unidimensional dengan beberapa anak panah dari konstruk ke indikator. Model hipotesis menunjukkan bahwa perubahan pada konstruk laten mempengaruhi perubahan pada indikator. Dalam model tersebut terdapat 2 variabel eksogen yaitu Gaya Kepemimpinan, Kepuasan Kerja dan satu variabel endogen yaitu Kinerja Tenaga Kependidikan. Pengujian hipotesis terdiri dari pengujian secara parsial dan determinasi. Berikut adalah hasil uji hipotesis. 


\section{Koefisien Parameter dan P Value}

Uji hipotesis dalam penelitian ini menggunakan Inner Model atau structural model, yang menggambarkan hubungan dan pengaruh antar variabel laten berdasarkan pada substantive theory. Uji signifikansi pengaruh antar konstruk dengan melihat nilai koefisien parameter dan nilai signifikansi $P$ Valuenya.

Tabel 2

Koefisien Parameter dan P Values

\begin{tabular}{|c|c|c|c|c|c|c|}
\hline \multicolumn{4}{|c|}{ Hipotesis } & Koefisien & $P$ & Kesimpulan \\
\hline $\begin{array}{c}\mathbf{H} \\
\mathbf{1}\end{array}$ & $\begin{array}{c}\text { Gaya } \\
\text { Kepemimpinan }\end{array}$ & $\rightarrow$ & $\begin{array}{l}\text { Kinerja Tenaga } \\
\text { Kependidikan }\end{array}$ & $-0,285$ & 0,126 & $\begin{array}{c}\text { Tidak } \\
\text { Terbukti }\end{array}$ \\
\hline $\begin{array}{l}\mathbf{H} \\
\mathbf{2}\end{array}$ & $\begin{array}{c}\text { Gaya } \\
\text { Kepemimpinan }\end{array}$ & $\rightarrow$ & Kepuasan Kerja & 0,641 & 0,000 & Terbukti \\
\hline $\begin{array}{l}\mathbf{H} \\
\mathbf{3}\end{array}$ & $\begin{array}{c}\text { Kepuasan } \\
\text { Kerja }\end{array}$ & $\rightarrow$ & $\begin{array}{l}\text { Kinerja Tenaga } \\
\text { Kependidikan }\end{array}$ & $-0,185$ & 0,355 & $\begin{array}{c}\text { Tidak } \\
\text { Terbukti }\end{array}$ \\
\hline
\end{tabular}

Berdasarkan Tabel 2 diperoleh adalah sebagai berikut : 1) Besarnya koefisien parameter variabel Gaya Kepemimpinan (X1) terhadap variabel Kinerja Tenaga Kependidikan (Y) sebesar -0.285 yang menunjukkan bahwa variabel Gaya Kepemimpinan (X1) terhadap variabel Kinerja Tenaga Kependidikan (Y) mempunyai pengaruh negatif. Sedangkan besarnya nilai $\mathrm{P}$ Values adalah (>0.05), sehingga nilai ini menunjukkan bahwa pengaruh variabel Gaya Kepemimpinan (X1) terhadap variabel Kinerja Tenaga Kependidikan (Y) adalah tidak signifikan; 2) Besarnya koefisien parameter variabel Gaya Kepemimpinan (X1) terhadap variabel Kepuasan Kerja (X2) sebesar 0.641 yang menunjukkan bahwa Gaya Kepemimpinan (X1) terhadap variabel Kepuasan Kerja (X2) mempunyai pengaruh positif. Sedangkan besarnya nilai $\mathrm{P}$ Values adalah $(<0.05)$, sehingga nilai ini menunjukkan bahwa pengaruh Gaya Kepemimpinan (X1) terhadap Kepuasan Kerja (X2) adalah signifikan; 3) Besarnya koefisien parameter variabel Kepuasan Kerja (X2) terhadap variabel Kinerja Tenaga Kependidikan (Y) sebesar -0.185 yang menunjukkan bahwa variabel Kepuasan Kerja (X2) terhadap variabel Kinerja Tenaga Kependidikan (Y) mempunyai pengaruh negatif. Sedangkan besarnya nilai $\mathrm{P}$ Values adalah $(>0.05)$, sehingga nilai ini menunjukkan bahwa pengaruh variabel Kepuasan Kerja (X2) terhadap variabel Kinerja Tenaga Kependidikan (Y) adalah tidak signifikan.

\section{Uji Hipotesis}

Analisis hipotesis pada hasil penelitian ini dapat dipaparkan sebagai berikut:

H1: Pengaruh Gaya Kepemimpinan (X1) terhadap Kinerja Tenaga Kependidikan (Y) di Universitas PGRI Yogyakarta.

Berdasarkan Tabel Koefisien Parameter dan P Values Gaya Kepemimpinan (X1) mempunyai pengaruh yang tidak signifikan terhadap Kinerja Tenaga Kependidikan (Y) di Universitas PGRI Yogyakarta. Bukti ini dilihat dari nilai P Values sebesar $0.126(>0.05)$ yang menunjukkan pengaruh tidak signifikan. Nilai 
original sampel sebesar -0.285 yang artinya bahwa variabel Gaya Kepemimpinan (X1) mampu memberikan pengaruh terhadap Kinerja Tenaga Kependidikan (Y) sebesar $-28.5 \%$. Hal ini berarti bahwa variabel Gaya Kepemimpinan (X1) memberikan pengaruh negatif dan tidak signifikan terhadap variabel Kinerja Tenaga Kependidikan (Y). Dengan demikian hipotesa Pertama (H1) di atas tidak terbukti, dan Gaya Kepemimpinan (X1) berpengaruh negatif terhadap Kinerja Tenaga Kependidikan (Y) di Universitas PGRI Yogyakarta.

\section{H2: Pengaruh Gaya Kepemimpinan (X1) terhadap Kepuasan Kerja (X2) di Universitas PGRI Yogyakarta.}

Berdasarkan Tabel Koefisien Parameter dan P Values Gaya Kepemimpinan (X1) mempunyai pengaruh yang signifikan terhadap Kepuasan Kerja (X2) di Universitas PGRI Yogyakarta. Bukti ini dilihat dari nilai P Values sebesar 0.000 $(<0.05)$ yang menunjukkan pengaruh yang signifikan. Nilai original sampel sebesar 0.641 yang artinya bahwa variabel Kepemimpinan (X1) mempunyai pengaruh yang signifikan terhadap Kepuasan Kerja (X2) sebesar 64,1\%. Hal ini berarti bahwa variabel Gaya Kepemimpinan (X1) memberikan pengaruh positif dan signifikan terhadap variabel Kepuasan Kerja (X2). Dengan demikian hipotesa Kedua (H2) di atas terbukti, dan Kepemimpinan (X1) mempunyai pengaruh yang positif terhadap Kepuasan Kerja (X2) di Universitas PGRI Yogyakarta.

\section{H3: Pengaruh Kepuasan Kerja (X2) terhadap Kinerja Tenaga Kependidikan (Y) di Universitas PGRI Yogyakarta.}

Berdasarkan Tabel Koefisien Parameter dan P Values Kepuasan Kerja (X2) mempunyai pengaruh yang tidak signifikan terhadap Kinerja Tenaga Kependidikan (Y) di Universitas PGRI Yogyakarta. Bukti ini dilihat dari nilai P Values sebesar 0.355 (>0.05) yang menunjukkan pengaruh tidak signifikan. Nilai original sampel sebesar -0.185 yang artinya bahwa variabel Kepuasan Kerja (X2) mampu memberikan pengaruh terhadap Kinerja Tenaga Kependidikan (Y) sebesar $-18.5 \%$. Hal ini berarti bahwa variabel Kepuasan Kerja (X2) memberikan pengaruh negatif dan tidak signifikan terhadap variabel Kinerja Tenaga Kependidikan (Y). Dengan demikian hipotesa ketiga (H3) di atas tidak terbukti, dan Kepuasan Kerja (X1) berpengaruh negatif terhadap Kinerja Tenaga Kependidikan (Y) di Universitas PGRI Yogyakarta.

\section{Koefisien Determinasi (R Square)}

Tabel 3

Koefisien Determinasi

\begin{tabular}{lccc}
\hline \multicolumn{1}{c}{ Pengujian } & $\begin{array}{c}\text { Hasil } \\
\text { Uji }\end{array}$ & $\begin{array}{c}\text { P } \\
\text { Value }\end{array}$ & Keterangan \\
\hline Gaya Kepemimpinan (X1) & - & - & - \\
Kepuasan Kerja (X2) & $\mathbf{0 , 4 1 1}$ & $\mathbf{0 . 0 0 0}$ & Signifikan \\
Kinerja Tenaga & $\mathbf{0 , 1 8 3}$ & $\mathbf{0 , 0 7 6}$ & Tidak Signifikan \\
Kependidikan (Y) & & & \\
\hline
\end{tabular}

Sumber : Calculated Model, Kelompok Goodness Of Fit, Tabel R-Square

Bisman (Bisnis dan Manajemen): The Journal Of Business and Management 
Dari hasil analisis pada uji Koefisien Determinasi $\left(\mathrm{R}^{2}\right)$ menunjukkan bahwa Kepuasan Kerja dipengaruhi oleh Gaya Kepemimpinan sebesar 41.1\% (0.411) sisanya sebesar $58.9 \%$ dipengaruhi faktor lain yang tidak terdapat dalam model, sedangkan untuk Kinerja Tenaga Kependidikan secara simultan dipengaruhi oleh Gaya Kepemimpinan dan Kepuasan Kerja sebesar 18.3\% (0.183) sisanya sebesar 81.7\% dipengaruhi faktor lain yang tidak terdapat dalam model. Dari hasil uji yang ada bahwa Kepuasan Kerja siginifikan dikarenakan dari hasil uji menunjukkan bahwa $\mathrm{P}$ Value $<0.05$, sedangkan Kinerja Tenaga Kependidikan tidak siginifikan dikarenakan dari hasil uji menunjukkan bahwa $\mathrm{P}$ Value $>0.05$, sedangkan pada pengujian variabel Gaya Kepemimpinan nilainya kosong karena tidak ada variabel yang menjelaskan.

\section{Analisis Jalur}

Analisis jalur merupakan metode analisis data multivarian yang digunakan untuk menguji hipotesis dengan tujuan untuk mengetahui pengaruh langsung dan tidak langsung seperangkat variabel penyebab terhadap variabel akibat.

Tabel 4

Koefisien Jalur

\begin{tabular}{cccc}
\hline $\begin{array}{c}\text { Pengaruh } \\
\text { Langsung }\end{array}$ & $\begin{array}{c}\text { Pengaruh Tidak } \\
\text { Langsung }\end{array}$ & Keterangan & Efek Total \\
\hline $\mathbf{( a )}$ & a X c $(\mathrm{d})$ & Pengaruh $\mathrm{X}_{1}$ & $\mathrm{a}+\mathrm{d}$ \\
$\mathbf{X 1} \rightarrow \mathbf{X} 2=$ & $\mathrm{X} 1 \rightarrow \mathrm{X} 2 \rightarrow \mathrm{Y}$ & terhadap $\mathrm{Y}$ & $0,641+(-0,118)=$ \\
$\mathbf{0 , 6 4 1}$ & $0,641 \times-0,185=-$ & melalui X2 & 0,523 \\
& 0,118 & &
\end{tabular}

(b)

$\mathrm{X} 1 \rightarrow \mathrm{Y}=-\mathbf{0 , 2 8 5}$

(c)

$\mathrm{X} 2 \rightarrow \mathrm{Y}=-\mathbf{0 , 1 8 5}$

Berdasarkan koefisien jalur pada Tabel 4 dapat diartikan sebagai berikut, Pengaruh antara Gaya Kepemimpinan (X1) terhadap Kepuasan Kerja (X2) dalam mempengaruhi Kinerja Tenaga Kependidikan (Y) adalah : $0.641+(-0.118)=$ $\mathbf{0 , 5 2 3}$ dapat meningkatkan efek pengaruh terhadap Kinerja dibandingkan pengaruh langsung Variabel Gaya Kepemipinan (X1) terhadap Kinerja Tenaga Kependidikan (Y) yang mempunyai nilai negatif sebesar -0.285 .

\section{KESIMPULAN DAN SARAN \\ Kesimpulan}

Kesimpulan diperoleh berdasarkan analisis deskriptif, analisis inferensial dan analisis jalur sebagai berikut : a) "Gaya Kepemimpinan (X1) mempunyai pengaruh yang tidak signifikan terhadap kinerja tenaga kependidikan (Y)". Hal ini berarti bahwa kinerja tenaga kependidikan tidak dipengaruhi oleh gaya kepemimpinan tetapi mereka bekerja pada organisasi atau institusi, dan kinerja tenaga kependidikan dipengaruhi oleh variabel lain yang belum diteliti dalam penelitian ini. Dengan demikian hipotesa pertama (H1) tidak terbukti; b) "Gaya 
Kepemimpian (X1) mempunyai pengaruh yang signifikan terhadap Kepuasan Kerja (X2)". Hal ini berarti kepuasan kerja tenaga kependidikan dipengaruhi oleh gaya kepemimpinan. Dengan demikian hipotesa kedua (H2) terbukti; c) "Kepuasan Kerja (X2) mempunyai pengaruh yang tidak signifikan terhadap kinerja tenaga kependidikan (Y)". Hal ini berarti bahwa kinerja tenaga kepenidikan tidak dipengaruhi oleh kepuasan kerja. Dengan demikian hipotesa ketiga (H3) tidak terbukti; d) Hasil analisis koefisen determinasi $\left(\mathrm{R}^{2}\right)$, kinerja tenaga kependidikan tidak signifikan dipengaruhi oleh gaya kepemimpinan dan kepuasan kerja, namun secara simultan dipengaruhi oleh gaya kepemimpinan dan kepuasan kerja. Hal ini terlihat dari analisis jalur yang digunakan untuk menguji hipotesis dengan tujuan mengetahui pengaruh langsung dan tidak langsung seperangkat variabel penyebab terhadap variabel akibat.

\section{Saran}

Berdasarkan hasil pembahasan dan kesimpulan yang diperoleh, maka saran yang dapat diberikan dalam penelitian ini yaitu :

\section{Bagi Perusahaan}

Disarankan organisasi maupun institusi harus bisa meningkatan kepuasan kerja tenaga kependidikan terutama pada kepuasan terhadap pendapatan, meskipun secara tidak langsung tidak mempengaruhi kinerja tenaga kependidikan Universitas PGRI Yogyakarta karena kinerja tenaga kependidikan Universitas PGRI Yogyakarta sangat baik. Tenaga kependidikan dalam kinerjanya tidak dipengaruhi oleh gaya kepemimpinan maupun kepusan kerja. Mereka bekerja pada organisasi atau institusi, yang artinya apa yang diharapkan oleh organisasi maupun institusi, tenaga kependidikan akan memberikan kinerja yang baik.

\section{Bagi penelitian selanjutnya}

Original Sample yang digunakan menunjukkan masih ada variabelvariabel lain yang dapat digunakan mempengaruhi kinerja tenaga kependidikan meskipun dalam penelitian ini kinerja tenaga kependidikan sudah sangat baik. 


\section{DAFTAR PUSTAKA}

AA. Anwar Prabu Mangkunegara, 2013, Manajemen Sumber Daya Manusia Perusahaan, Remaja Rosdakarya, Bandung.

Fahmi, Irham (2011). Manajemen Teori, Kasus dan Solusi. Bandung : Alfabeta.

Fahmi, Irham (2013). Perilaku Organisasi. Teori, Aplikasi Dan Kasus. Bandung: Alfabeta.

Hidayat, Aris., Sudirja., Kohar, Nanang., 2018, Analisa Pengaruh Gaya Kepemimpinan terhadap Kinerja Pegawai pada Suku Dinas Kebersihan Kota Administrasi Jakarta Timur, Managerial-Jurnal Penelitian ilmu Manajemen, Vol. 1 No. 12018.

Mandey, Maya A, dan V.P.K. Lengkong, 2015, Pengaruh Kompensasi, Gaya Kepemimpinan dan Lingkungan Kerja terhadap Kinerja Pegawai (Studi pada Fakultas Ekonomi dan Bisnis Unsrat). Jurnal EMBA Vol. 3 No.3 Sept. 2015. Hal 1383-1394.

Mathis, R dan Jackson, W.2006. Human Resources Development (Track MBA series/terjemahan). Jakarta; Prestasi Pustaka

Purwanto dan Wahyuddin, "Pengaruh Faktor-faktor Kepuasan Kerja terhadap Kinerja Karyawan”, Artikel Kepuasan Kerja, diakses tanggal 17 Jaunari 2015.

Rani Mariam, 2009, Pengaruh Gaya Kepemimpian dan Budaya Organisasi terhadap Kinerja Karyawan melalui Kepuasan Kerja Karyawan sebagai Variabel intervening \{studi pada kantor Pusat PT Asuransi Jaya Indosesia (Persero)

Robbins, Stephen, P., 2008. OrganizationalBehavior, Tent Edition (Perilaku Organisasi Edisi ke Sepuluh), Alih Bahasa Drs. Benyamin Molan. Jakarta : PT. Macanan Jaya Cemerlang.

Sugiyono, 2015. Metode Penelitian kombinasi (Mix Methods). Bandung : Alfabeta.

Wibowo, 2013. Manajemen Kinerja, Jakarta : PT Rajagrafindo Persada.

Wibowo, 2013. Manajemen Kinerja : Jakarta Rajawali Pers.

Wiyono, Gendro, 2011, Merancang Penelitian Bisnis dengan Alat Analisis, SPSS 17.0 dan Smart PLS, UPP STIM YKPN. 
12 | Bisman: Volume 3. Nomor 1, Februari 2020.

Wukir. 2013. Manajemen Sumber Daya Manusia dalam Organisasi Sekolah. Yogyakarta: Multi Presindo.

Yuniarti, Dwi., Suprianto, Erlan., (2014), Pengaruh Gaya Kepemimpinan dan Tingkat Pendidikan terhadap Kinerja Karyawan pada Direktorat Operasi/Produksi PT.X, INDEPT, Vo. 4, No. 1 Februarai 2014. 